\title{
Human Cells, Tissues, and Cellular and Tissue-Based Products Satellite Recovery Facility
}

National Cancer Institute

\section{Source}

National Cancer Institute. Human Cells, Tissues, and Cellular and Tissue-Based Products Satellite Recovery Facility. NCI Thesaurus. Code C133321.

A facility with Human Cells, T issues, and Cellular and T issue-Based Products (HCT /Ps) recovery as the primary operation and a parent establishment that has a registration number. 